\title{
Gamification: Fuelish or foolish?
}

\author{
George Leslie Hicks, Jr, MD
}

From the Department of Surgery, University of Rochester Medical Center, Rochester, NY.

Disclosures: Author has nothing to disclose with regard to commercial support.

Received for publication Aug 7, 2015; accepted for publication Aug 8, 2015; available ahead of print Sept 15, 2015.

Address for reprints: George Leslie Hicks, Jr, MD, Department of Surgery, University of Rochester Medical

Center, Rochester, NY 14642 (E-mail: george_hicks@urmc.rochester.edu).

J Thorac Cardiovasc Surg 2015;150:1059-60

$0022-5223 / \$ 36.00$

Copyright (C) 2015 by The American Association for Thoracic Surgery

http://dx.doi.org/10.1016/j.jtcvs.2015.08.018

The study in this issue of the Journal entitled, "Gamification in Thoracic Surgical Education: Using Competition to Fuel Performance," efforts of the Joint Council of Thoracic Surgery Education and the Thoracic Surgery Directors Association in hopes of stimulating the appetites of cardiothoracic residents to increase their technical skills and cognitive performances during cardiothoracic training. The Jeopardy and Top Gun competitions, held at the Spring 2015 American Association for Thoracic Surgery meeting and analyzed in the article, represent a novel and "fun" approach to accomplish intellectual and technical skill achievements with the aid of coaching by dedicated faculty. The chosen residents were selected on the basis of closed-book online examination performances and video analyses as being the best of the best (among those who applied). Thus one should not be surprised that they present as high achievers with high in-training examination scores as well as a high level of preparedness (through practice) in terms of the skill tested (small vessel anastomosis). The residents and the program directors are to be congratulated on their commitment to promote education, and the enthusiasm surrounding the event speaks to the use of new approaches in helping our residents learn to become better both technically and cognitively.

The study authors of course have some conflict of interest, because some of these authors are the originators of the Thoracic Surgery Curriculum (TSC) and others are part of the sponsoring societies. Rightfully, they want to stimulate use of the newly developed TSC, now in its electronic iteration as the Web Brain, thereby justifying the expense of production as well as to demonstrate its usefulness to cardiothoracic residents at large. This conflict of interest is unavoidable and does not tarnish the purpose of the article, which is to build on the enthusiasm for cardiothoracic surgery among current surgical residents and medical students. These authors want to be on the educational vanguard of this momentum by suggesting new methods for learning and skills training that use the modalities of TSC and simulation-based technical trainers. It is true that these authors do not have proof that the TSC

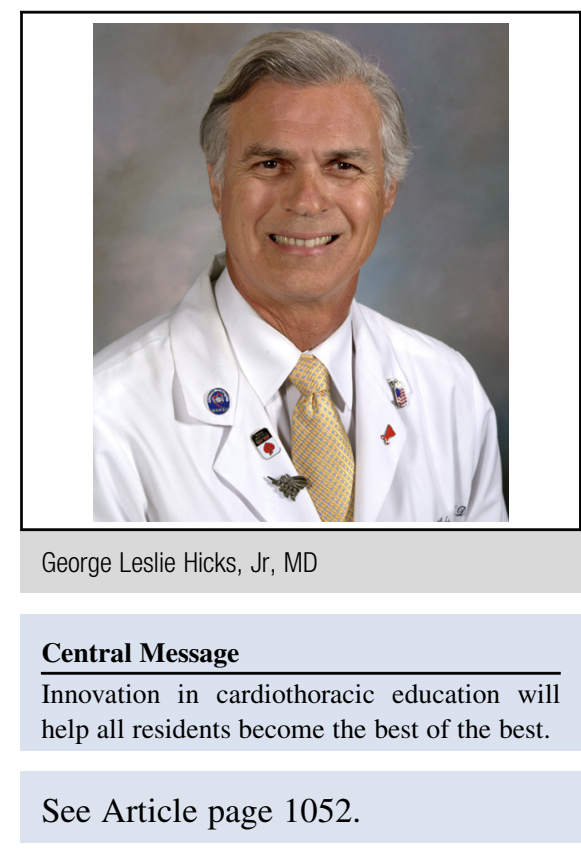

was the main source of cognitive preparation for the Jeopardy rounds (as this currently cannot be documented), and likewise they cannot show that sewing a fast and precise anastomosis under pressure equates to better performance in the operating room. It was clear, however, that those residents who were selected on the basis of their technical skills and foundation of knowledge as demonstrated in the initial screening examination and videos were extremely well prepared for the competition, a trait that could only help them in their pursuit of mastering the complexities of the operating room setting.

Cardiothoracic surgery is making a resurgence in popularity, and it is innovative approaches such as these competitions that stimulate and invigorate the learning and training process. The article is a testimony to the competitiveness and hunger that our residents have to learn, and it is to be hoped that this attitude will continue to grow throughout the programs in the country to produce the best of the best in all our residents. The article should not be construed as a clarion call to flaunt competition as the only means to optimize the educational process for residents so that they are autonomous, safe and ready for the ardors of cardiothoracic surgery in practice. Rather, it should be an example to all program directors that there are many ways to stimulate learning, including simulation for technical skills, team training for emergency scenarios, and new methods for the objectification of cognitive knowledge mastery. 
It should be recognized that gamification is an "external" form of motivation and that clearly the residents involved in these 2 activities are highly internally motivated. It is this internal motivation that cardiothoracic educators and program directors are trying to nurture and bring forth in all of our trainees. Simulation experience such as Boot Camp have been enthusiastically received by all residents in attendance, and methods to improve cognitive learning, although still needing a personal commitment from each resident, can be augmented and elevated by educationally sensitive and dedicated faculty. Each of our residents deserves to be the best of the best, and as cardiothoracic educators we owe it to them to embrace all types of educational platforms (operating room, simulation, TSC, emergency scenario training, and others) to prepare them optimally for the future. This article's authors are to be congratulated for their enthusiasm, hard work, and innovation on behalf of all our residents, beginning with a spark of challenge that might become a widespread conflagration of new ideas and methods to truly prepare our residents to be the best of the best, improving patient outcomes in the future.

\section{Reference}

1. Mokadam NA, Lee R, Vaporciyan AA, Walker JD, Cerfolio RJ, Hermsen JL, et al. Gamification in thoracic surgical education: Using competition to fuel performance. J Thoracic Cardiovasc Surg. 2015;150:1052-8. 